\title{
Desafios e tecnologia na psicoterapia cognitiva do TDAHna infância: seguimento de umano de caso de gêmeos monozigóticos
}

Rodrigo Grassi de Oliveira ${ }^{1}$

Carla Bicca ${ }^{2}$

Recebido: 24/9/2003 Aceito: 6/10/2003

RESUMO

A escolha do caso deve-se a quatro principais motivos: (1) a alta complexidade do caso dificulta o diagnóstico, a abordagem psicofarmacológica e psicoterápica; (2) as dificuldades logísticas comuns aos profissionais e pacientes do Sistema Único de Saúde (SUS), como dificuldades econômicas e assistenciais, que dificultam o tratamento; (3) a importância da combinação tecnológica de diferentes modelos de terapias cognitivas na abordagem do TDAH, fundamental para alguns casos; (4) e a importância da viabilização proporcionada pelo Programa de Residência quando permite a busca por auxílio externo, em termos de supervisão, o que potencializa a capacitação do residente. Unitermos: Transtorno de déficit de atenção e hiperatividade; Terapia cognitiva; Gêmeos monozigotos.

\section{ABSTRACT}

Challenges and technology in the cognitive psychotherapy of childhood ADHD: one-year follow-up of monozygotic twins

The authors describe the follow-up of monozigotic twins treated with cognitive therapy for attention deficit hyperactivity disorder.

Keywords: Attention deficit hyperactivity disorder; Cognitive therapy; Monozigotic twins.

\section{Identificação}

Felipe e Lucas (nomes fictícios), 8 anos (DN: 25/6/94), gêmeos monozigóticos, brancos, sexo masculino, religião católica, $2^{\underline{a}}$ série do Ensino Fundamental incompleta, estudantes, naturais e procedentes de Porto Alegre.

\section{Queixa principal}

Inquietude, agressividade, impulsividade e dificuldade para ler desde os 4 anos.

\section{História da doença atual}

\section{Prévia ao atendimento}

Felipe veio à consulta no Ambulatório de Neuropsiquiatria do HMIPV, em maio de 2001, encaminhado pelo Serviço Social, a pedido de Catarina, sua mãe adotiva.

Catarina trouxe Felipe à primeira consulta (então com 6 anos) referindo que, há três meses, teria o encontrado deitado de bruços em um sofá, como se estivesse dormindo, porém "babando muito". Na ocasião,

\footnotetext{
Residente do segundo ano do Programa de Residência em Psiquiatria da FFFCMPA/HMIPV da cidade de Porto Alegre/RS e Mestrando no Grupo de Pesquisa em Processos Cognitivos da Psicologia da PUCRS.

2 Mestre em Clínica Médica pela UFRGS, Psicoterapeuta Cognitivista e Comportamental e Supervisora Colaboradora do Programa de Residência em Psiquiatria da FFFCMPA/HMIPV da cidade de Porto Alegre/RS.

Endereço para correspondência:

Rodrigo Grassi de Oliveira

Av. Iguaçu, 443/301 - Bairro Petrópolis

Porto Alegre, RS - CEP 90470-430

E-mail: rodrigo_grassi@terra.com.br
} 
colocou-o embaixo do chuveiro com água fria sem conseguir reanimá-lo. O paciente foi levado a um hospital público, onde foi diagnosticada "crise convulsiva", sendo realizado EEG que evidenciou "alterações paroxísticas focais de moderada intensidade, apresentando-se de forma dilatada e independente em ambas as regiões temporoccipitais, com predomínio do hemisfério esquerdo". Foi iniciado tratamento com carbamazepina $20 \mathrm{mg} / \mathrm{kg} / \mathrm{dia}$ e, por falta de vagas, ele não continuou o atendimento naquele hospital. Permaneceu três meses sem acompanhamento médico, apenas usando essa medicação.

Nessa consulta, a mãe encontrava-se muito ansiosa, prolixa e redundante, não conseguindo manter um diálogo claro com o médico assistente. Catarina contou que Felipe teria um irmão gêmeo com "os mesmos problemas". A criança mostrava-se extremamente negativista, envergonhada, olhando para baixo, apertando as mãos como se estivesse amassando algo. Não parava quieta um único minuto, além de passar a idéia de estar completamente alheia ao que estava sendo conversado. Quando era solicitada a falar, parecia não escutar e era violentamente criticada por Catarina: "Desembucha! Fala com o médico! Você vai se ver comigo em casa!". Em virtude dessa agitação de Felipe, o médico assistente optou por manter a dose de carbamazepina e marcar uma consulta com os dois irmãos em 30 dias.

Na segunda avaliação, vieram à consulta Felipe e Lucas, idênticos, porém Felipe parecendo bem mais desenvolvido física e intelectualmente que Lucas. Os dois pulavam de um lado para outro e na investigação clínica foi constatado que esse comportamento era constante em casa, que tinham muita dificuldade de ficar sentados em sala de aula e de seguir qualquer tipo de orientação, nunca terminando suas tarefas. Também se envolviam em atividades perigosas como subir em telhados, descer uma lomba muito íngreme com a bicicleta e brigar com crianças mais velhas. Apresentavam ainda dificuldade de relacionamento, agressividade, déficit de aprendizagem e humor deprimido, caracterizando o diagnóstico de TDAH, portanto foi iniciado tratamento com imipramina (IMI) $25 \mathrm{mg} / \mathrm{dia}$.

Nos meses subseqüentes as crianças tiveram uma discreta melhora e a IMI acabou sendo aumentada para $50 \mathrm{mg} /$ dia. Conseguiram passar de ano (da primeira para a segunda série), mas com muita dificuldade para ler e escrever. Neste período Felipe foi avaliado pelo teste de WISC e obteve prejuízo importante na categoria de abstração e atenção, ficando com um escore compatível com inteligência limítrofe (QI: 74). Posteriormente, Lucas também foi testado, e as áreas de prejuízo foram as mesmas do irmão, todavia seu escore acabou sendo compatível com retardo mental leve (QI: 69).

\section{Início do atendimento}

Iniciou-se o atendimento de Lucas e Felipe em janeiro de 2002. Eles chegam ao consultório com a mãe adotiva e sentam-se juntos em uma única cadeira. Abraçam-se e, quando os cumprimento, riem e abaixam a cabeça. Catarina inicia a contar desorganizadamente a história prévia dos gêmeos, que cada vez mais se torna confusa e difícil de entender. Ela conta vinhetas biográficas suas, da época em que os gêmeos nasceram, de fatos recentes, facetas da personalidade de seu marido e confunde tudo cada vez mais. Não há como interrompê-la, pois, na mesma velocidade com que Catarina relata a história, Felipe e Lucas pulam em cima da mesa, chutam a porta, riem sem parar e só param um pouco quando são interpelados por gritos de sua mãe: "Eu vou abandonar vocês na Febem! Não agüento mais!”. A consulta está fora de controle. Não sabemos se ficamos ou saímos da sala. Pedimos para Catarina parar de falar e reiniciamos a investigação da história pessoal de seus filhos, utilizando o método socrático; não adianta e, em alguns segundos, frases como "Esses aí são filhos de uma bêbada que fugiu e me deixou para criar", "A mãe deles não presta!" "pipocam" na metodologia de coleta de informações. Solicitamos, com certa austeridade, que a mãe se retire e tentamos falar sozinhos com os gêmeos, porém já não temos mais autoridade e somos ignorados por ambos. Discutimos o caso com a neurologista supervisora, aumentamos a IMI para $75 \mathrm{mg}$ e marcamos nova consulta para 30 dias.

Retornam com uma melhora discreta e decidem verbalizar que gostariam de estar "bem longe". Respondem em coro às perguntas, mesmo quando dirigidas para um. Pedimos para um só ficar na sala, mas esta tarefa é tão impossível quanto pedir para eles prestarem atenção. Percebemos que eles são uma unidade. Desconfiam de tudo e todos. A ameaça de abandono é constante e verbalizada por Catarina a cada minuto: "Vou devolver vocês". A supervisora orienta encaminhar o caso para atendimento psicoterápico. $\mathrm{O}$ modelo escolhido é a terapia cognitiva, que se inicia em março de 2002.

\section{História pessoal e social}

Os pacientes nasceram frutos de um estupro ( $\mathrm{sic}$ ), parto normal, prematuros (com 6 meses), sem registro de peso. Ficaram internados por um mês para ganhar peso. Não foram amamentados no peito. Lucas teve meningite neonatal, ficando internado mais seis meses.

Catarina relata que, enquanto Lucas estava internado, Felipe ficou com sua mãe biológica (Rosa) e que esta se negou a ver o primeiro, inclusive tentando matar a criança durante a internação (sic). Após a alta, Lucas sempre viveu com Catarina e sua família. Felipe, até os 
4 anos, era "abandonado" freqüentemente com Catarina, quando Rosa estava muito deprimida ou em uso pesado de álcool. Ficava uns dois meses e era retirado da casa de Catarina por outros dois meses e assim sucessivamente. Catarina conta que Lucas só falava e queria sair de casa quando Felipe estava presente. Cada vez que Felipe era levado por Rosa, Lucas emudecia e insistia em ficar em casa, chorando constantemente. Por fim, aos 4 anos Felipe e Lucas foram levados por seu pai biológico para morar com ele. Isso durou um mês e as crianças voltaram emagrecidas e muito assustadas, contando que teriam apanhado. Catarina acredita que "o pior aconteceu", referindo-se a um pretenso abuso sexual.

Após esse episódio as crianças ficaram definitivamente com Catarina, que obteve tutela provisória e, no ano de 2002, o pátrio poder.

Os familiares dizem que eram crianças muito choronas, apegadas à mãe adotiva e inquietas por demais. Referem terror noturno e ansiedade de separação.

Iniciaram no colégio com desempenho medíocre, mas conseguiram passar de ano na primeira série, repetindo na segunda.

Lucas e Felipe andam sempre juntos e o desenvolvimento de um depende da presença do outro, o que é verbalizado por ambos.

\section{História familiar}

A mãe biológica, Rosa, 39 anos, é ex-faxineira, etilista e apresenta diagnóstico de transtorno afetivo bipolar (TAB). A família materna nunca reconheceu os gêmeos como parte da família.

Osvaldo, 53 anos, ex-companheiro de Rosa, portador de seqüela neurológica após TCE e etilista, foi quem registrou os gêmeos e é quem as crianças acreditam ser seu pai biológico. Todavia, o verdadeiro pai biológico de Felipe e Lucas parece ser um irmão desse ex-companheiro, que, segundo Rosa, a teria estuprado.

Os gêmeos possuem três irmãos biológicos por parte de mãe: uma irmã de 9 anos (história de enurese e estar "sempre chorando"), um irmão de 14 anos (hígido) e um de 19 anos (etilista).

A família adotiva é composta por Catarina, 48 anos, esposa de Osvaldo, 52 anos, irmão de Luis. Catarina possui diabetes melito (DM), TAB tipo II e traços de personalidade borderline. Luis é etilista e tem câncer de estômago. Possuem três filhas (23, 21 e 20 anos) e um filho (17 anos).

O casal, o filho e os gêmeos vivem em uma casa com dois quartos. Nos fundos da casa moram as filhas.

\section{Exame clínico pediátrico e exames complementares}

A avaliação pediátrica é normal para ambas as crianças, inclusive o exame neuropediátrico. Da mesma forma estão os exames laboratoriais (hemograma, provas de função hepática, renal e tireoideana e marcadores infecciosos) e eletrofisiológicos (EEG, ECG).

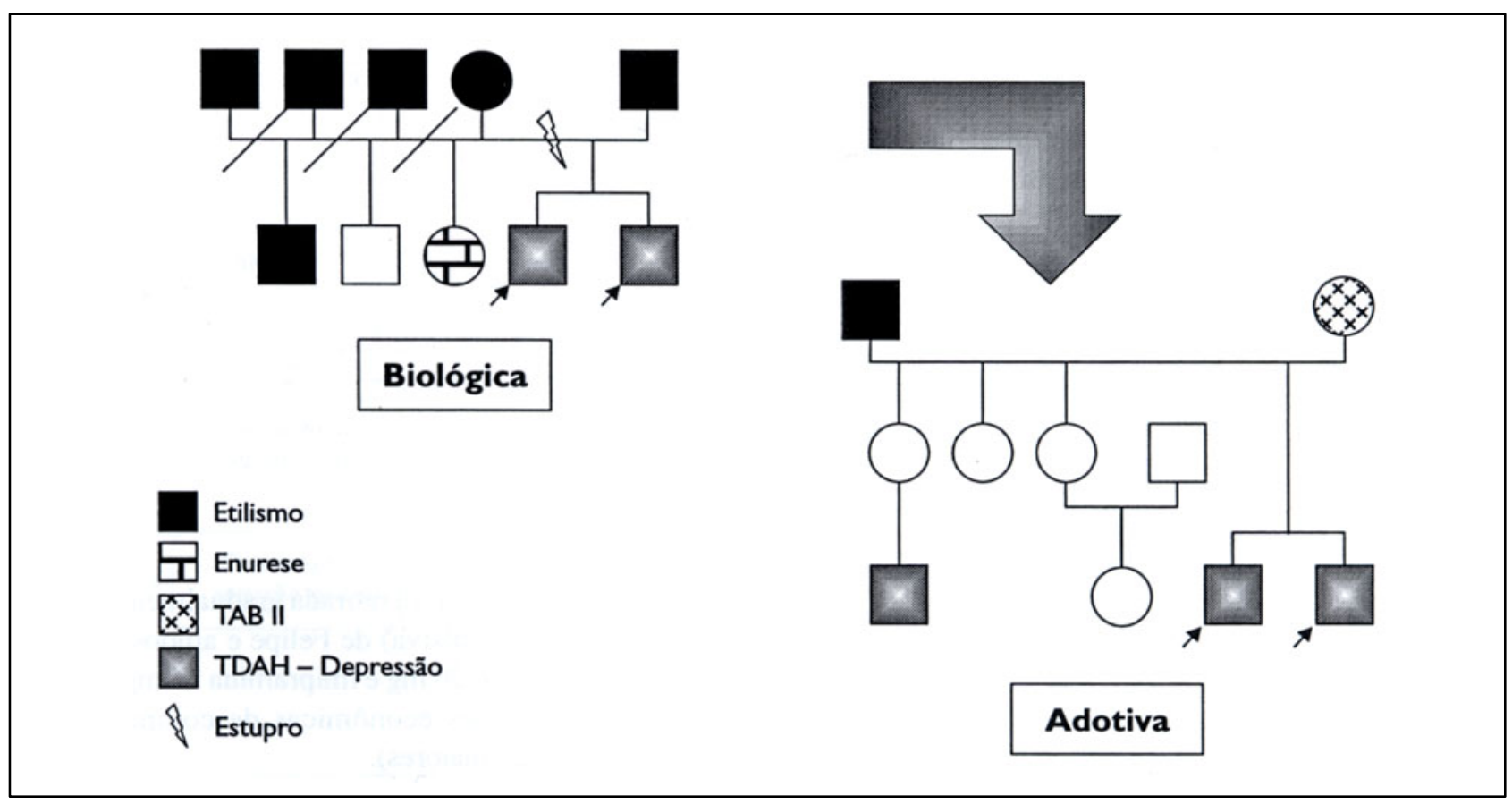

Figura 1 - Genetograma da família. 
Exame do estado mental (EEM)

$\mathrm{Na}$ época do primeiro atendimento as crianças apresentavam hipervigilância e hipotenacidade, sem alterações na sensopercepção, memória imediata prejudicada, desorientados quanto ao tempo, lúcidos, com idéias de culpa e autodepreciação, oscilação entre mutismo seletivo e respostas em coro, empobrecimento intelectual, afeto exaltado, humor disfórico e conduta de hiperatividade, opositora e negativista.

No EEM atual as crianças não apresentam achados significativos.

\section{Hipóteses diagnósticas}

Eixo I Transtorno de déficit de atenção e hiperatividade (F90.0);

Episódio depressivo grave sem sintomas psicóticos (F32.2);

Transtorno afetivo bipolar, episódio grave sem sintomas psicóticos (F31.4).

Eixo II A investigar.

Eixo III Meningite neonatal (Lucas);

Crise convulsiva aos 5 anos (Felipe).

Eixo IV • problemas relacionados à educação e à alfabetização (Z55);

- outros problemas específicos relacionados ao ambiente social (Z60.8);

- supervisão e controle parentais inadequados (Z62.0);

- problemas de relacionamento com parentes consangüíneos e por afinidade (Z63.1);

- ausência de membro na família (Z63.3);

- história familiar de abuso de álcool (Z81.1), retardo mental (Z81.0), drogas (Z81.3) e transtornos mentais outros (Z81.8).

Eixo V - A Autocuidados: 3;

- B Ocupação: 5;

- C Família: 4;

- D Social: 5.

\section{Evolução}

Felipe e Lucas iniciaram atendimento psicoterápico com um residente do primeiro ano por alguns motivos:
1. Não há serviço de Psiquiatria Infantil e a espera para atendimento na comunidade pode demorar de meses a anos;

2. A família não tinha condições financeiras para atendimento privado;

3. O Programa de Residência proporcionou a possibilidade de buscar supervisão especializada externa;

4. Era crucial o atendimento psicoterápico a curto prazo;

5. O residente já estava fazendo formação em Psicoterapia Cognitiva.

Os gêmeos não conseguiram passar de ano, porém nos últimos dois meses letivos estavam copiando e fazendo as tarefas.

Atualmente, mudaram de colégio, estão juntos na classe, Felipe é o melhor aluno da turma e Lucas mantém a média com os colegas, ambos com avaliação escolar muito boa. Observa-se mudança na crença central e melhora dos sintomas do TDAH clinicamente e conforme o gráfico da escala SWAN.

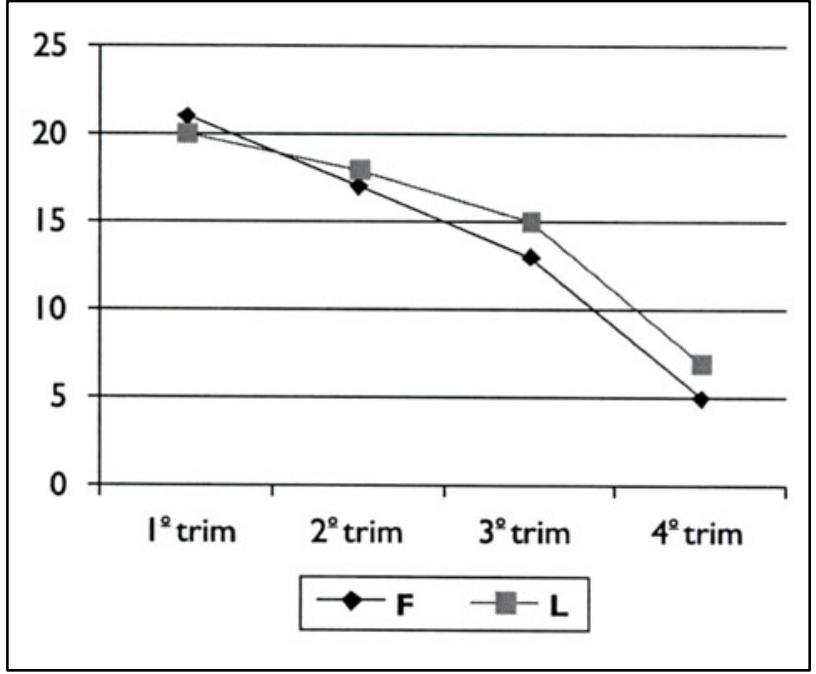

Figura 2 - Gráfico de evolução dos sintomas de TDAH, aferidos pela escala de SWAN, durante um ano de atendimento.

A carbamazepina foi retirada gradualmente (a indicação era crise convulsiva) de Felipe e ambos estão em uso de metilfenidato $20 \mathrm{mg}$ e imipramina $75 \mathrm{mg}$ (por não possuírem condições econômicas de comprar metilfenidato em doses maiores).

Foram retestados pelo WISC e ambos obtiveram escores compatíveis com inteligência normal. 


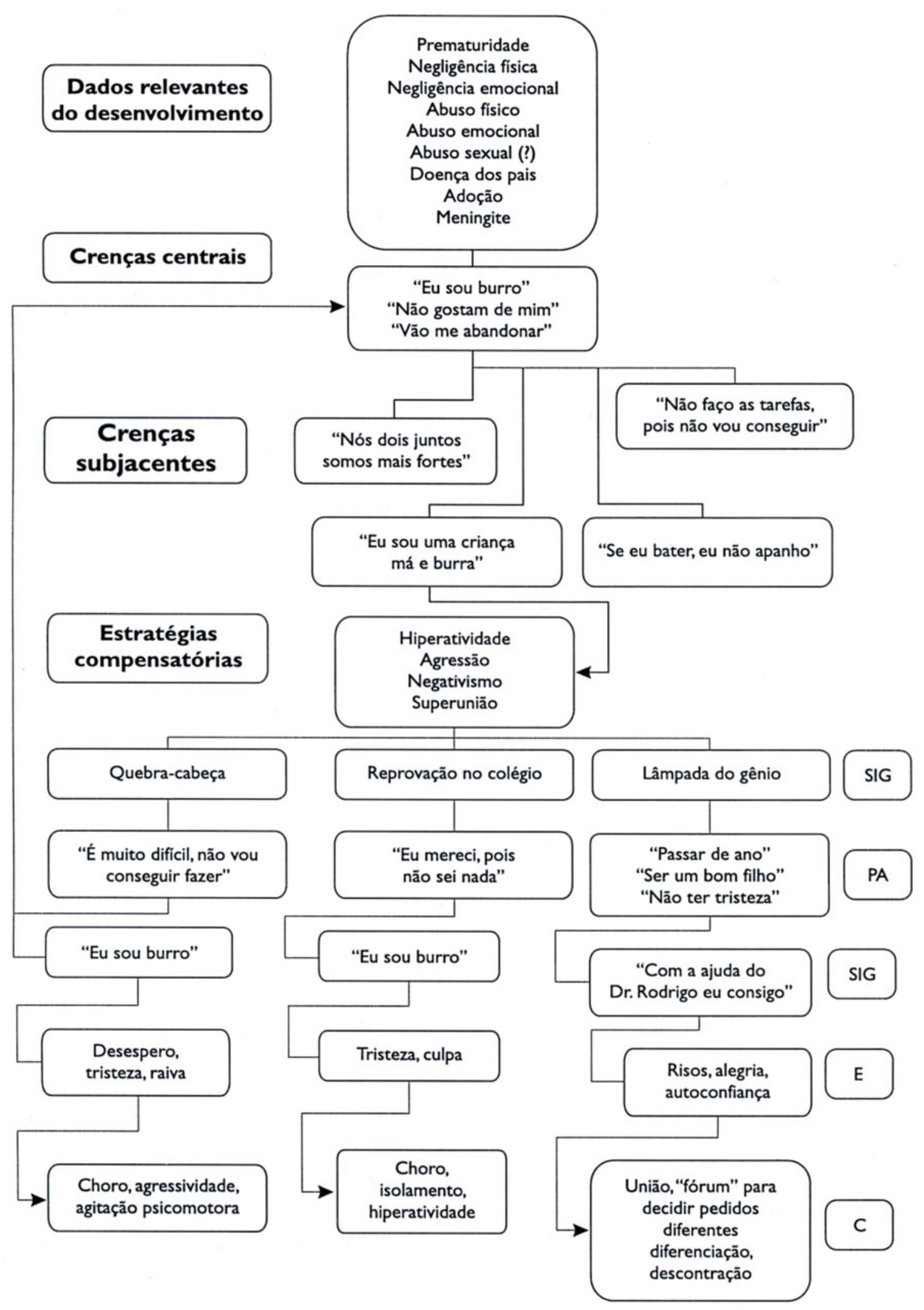

Figura 3 - Diagrama cognitivo.

SIT - Situação; PA - Pensamento automático; SIG - Significado; E - Emoção; C - Conduta. 